\title{
Early Results of Mitral Valve Replacement in Severe Pulmonary Artery Hypertension-An Institutional Prospective Study
}

\author{
Nirmal Kumar ${ }^{1 *}$, Prashant Sevta ${ }^{2}$, Subodh Satyarthy ${ }^{1}$, Saket Agarwal ${ }^{1}$, \\ Vithal Kumar Betigeri ${ }^{1}$, Deepak Kumar Satsangi ${ }^{1}$ \\ ${ }^{1}$ Department of Cardiothoracic and Vascular Surgery, G. B. Pant Hospital, New Delhi, India \\ ${ }^{2}$ Department of Cardiothoracic and Vascular Surgery, Escorts Heart Institute and Research Center, New Delhi, India \\ Email: "nirmalk20@gmail.com
}

Received March 25, 2013; revised April 25, 2013; accepted May 3, 2013

Copyright (C) 2013 Nirmal Kumar et al. This is an open access article distributed under the Creative Commons Attribution License, which permits unrestricted use, distribution, and reproduction in any medium, provided the original work is properly cited.

\begin{abstract}
Introduction: In patients undergoing surgery for mitral valve replacement (MVR) for valvular heart disease, pulmonary artery hypertension $(\mathrm{PAH})$ has been considered a major risk factor. In this prospective study, we have studied the early hemodynamic changes and post-operative outcomes of MVR among patients with severe PAH. Methods: 68 consecutive patients who underwent mitral valve replacement for severe rheumatic mitral valve disease with severe PAH (pulmonary artery pressure (PAP) $>50 \mathrm{mmHg}$ ) were studied prospectively for immediate postoperative hemodynamics and outcomes. The mean age of the patients was 32.1 years. 32 (47.05\%) patients had mitral stenosis, $13(19.11 \%)$ had mitral regurgitation and $23(33.82 \%)$ had mixed lesions. Patients were divided into two groups based on preoperative pulmonary artery pressures. In 56 patients $(82.35 \%$, group I) PAP was sub-systemic or systemic, with a mean of 58.4 mmHg. Twelve patients (17.65\%, group II) had supra-systemic PAP with a mean of $82.4 \mathrm{mmHg}$. Results: After mitral valve replacement, the PAP and pulmonary vascular resistance (PVR) decreased significantly in group I to near normal levels. In group II also the PAP and PVR decreased significantly but significant residual PAH remained. Operative mortality was 3.5\% in group I and $16.6 \%$ in group II. Conclusions: MVR is safe and effective at the presence of severe $\mathrm{PAH}$ as long as the PAP is below or equal to systemic pressures. With suprasystemic PAP, MVR carries a high risk of mortality and the patient continues to have severe PAH in the postoperative period.
\end{abstract}

Keywords: Pulmonary Artery Hypertension; Mitral Valve Replacement

\section{Introduction}

Rheumatic heart disease is common in the developing countries, and its incidence in India is high and is the leading cause of valvular heart disease. A significant number of people do not receive adequate nutrition, sanitation and medical care and live in congested colonies. Consequently, they suffer from recurrent attacks of rheumatic fever, and severe valvular disease develops within 5 years of the initial episode [1]. Patients with mitral valve disease are therefore young when they present for surgery, usually in the second to third decade of life. A substantial number of patients especially from rural areas present at a very late stage of the disease when the pulmonary artery pressure (PAP) is very high, at times near-

"Corresponding author. ing the systemic pressure. In the initial stages, pulmonary hypertension may be confined to the pulmonary veins, but later pulmonary arterial hypertension (PAH) supervenes. The accompanying increase in pulmonary vascular resistance (PVR) caused by organic changes in the pulmonary vasculature further complicates the issue.

The development of pulmonary arterial hypertension (PAH) has long been considered a risk factor for poor outcome in patients undergoing mitral valve replacement (MVR), with operative mortality ranging from $15 \%$ to $31 \%[2,3]$. This prospective study was conducted to assess the early postoperative hemodynamics changes and mortality following MVR in the presence of severe PAH.

\section{Material and Methods}

This prospective study was conducted at our tertiary care 
centre which is a major referral centre for patients from north India. The study period was from September 2009 to August 2010. There were 272 isolated MVR operations performed during this period for severe rheumatic mitral valve disease. On preoperative echocardiography, patients who were found to have severe PAH based on estimated right ventricular systolic pressures $>50 \mathrm{mmHg}$ were enrolled in the study. Patients with severe PAH were electively not planned for mitral valve repair as per institutional protocol. Patients were divided into two groups: group I were patients with systemic or sub-systemic PA pressures; group II patients had supra-systemic PA pressures. The groups were comparable with respect to age, sex, height, weight, body surface area, New York Heart Association (NYHA) functional class and the presence of preoperative atrial fibrillation. Patients in both groups were on a similar treatment regimen that consisted of loop diuretics, digoxin, beta blocker, angiotensin-converting enzyme inhibitor and calcium channel blockers.

All preoperative assessments were carried out by 2dimensional transthoracic echocardiography. Cardiac catheterization was not undertaken in any of these patients as per institutional protocol. Patients more than 40 years of age underwent isolated coronary angiography to rule out coronary artery disease. After due informed consent, all patients underwent MVR with bioprosthetic or mechanical valve. On arrival in the operating room, continuous electrocardiographic monitoring was started and invasive arterial blood pressure recording established. A 5-lumen pulmonary artery catheter $(7.5 \mathrm{~F})$ with a rapidresponse thermistor probe (Edwards Lifesciences LLC, Irvine, CA) was then inserted via the right internal jugular vein.

Cardiac output (CO) was measured by the thermodilution technique using $10 \mathrm{~mL}$ of $0.9 \%$ ice-cold saline and a hemodynamic monitor (DatexEngstrom AS/3, Helsinki, Finland) having inbuilt capacity to measure $\mathrm{CO}$ and calculate hemodynamic parameters. Three consecutive successful determinations were averaged, provided the difference between any two readings did not exceed $15 \%$. Mean and systolic pulmonary artery pressure, pulmonary capillary wedge pressure (PCWP), pulmonary vascular resistance (PVR) and cardiac index (CI) were calculated. Baseline (control) hemodynamic and arterial blood gas $(\mathrm{ABG})$ measurements were obtained before the induction of anesthesia. General anaesthesia was induced with fentanyl $8-10 \mu \mathrm{g} / \mathrm{kg}$ and thiopental $1 \mathrm{mg} / \mathrm{kg}$. Rocuronium and vecuronium were used as muscle relaxants. Measurements were again obtained after induction, immediately after MVR when the patient had been weaned from cardiopulmonary bypass (CPB) and the hemodynamics had been stabilized, 6 hours and 24 hours and 48 hours after the operation.

\section{Technique of MVR}

All patients were operated on CPB under moderate hypothermia $\left(28^{\circ} \mathrm{C}-30^{\circ} \mathrm{C}\right)$ using standard techniques. Mitral valve was approached either through the left atrium or via the interatrial septum (trans-septal approach). Whenever possible, total chordal preservation was carried out. The valve used was ATS (Advancing The Standards, Minneapolis, MN) bileaflet mechanical prosthesis in 50 patients and Carpentier Edward (Edwards Lifesciences, Irvine, California) (bioprosthetic valve) in 18 patients. Intra-operative trans-esophageal echocardiography was done in all patients and it did not reveal any significant gradient across the prosthesis or paravalvular leak in any patient. No patient required reinstitution of cardiopulmonary bypass.

All patients were given narcotic analgesics and vasodilator infusion in the form of nitroglycerine apart from the inotropes (dopamine, adrenaline and dobutamine), which were discontinued when the hemodynamics had stabilized and they could be extubated. No patient required intra-aortic balloon pump. Inhalational nitric oxide could not be used due to its non-availability at our centre.

\section{Statistical Analysis}

All values are mentioned as mean \pm standard deviation (SD) and range. Unpaired Student's t test and chi-square test were used for comparison of data of the two groups, where applicable. For statistical analysis, the statisticalsoftware SPSS version 19.0 for windows (SPSS Inc., Chicago, IL) was used. A p value $<0.05$ was considered statistically significant.

\section{Results}

On preoperative echocardiography, 68 (25\%) patients were found to have severe PAH based on estimated right ventricular systolic pressures $>50 \mathrm{mmHg}$. Group I had 56 patients $(82.35 \%)$ whereas 12 patients $(17.65 \%)$ were in group II. These patients were between 15 and 47 years of age, with a mean age of 32.1 years. The duration of symptoms ranged from 5 months to 12 years and was comparable in both the groups. In group I, the dominant valvular lesion was mitral stenosis (MS) in $24(42.8 \%)$ patients, mitral regurgitation (MR) 12 patients $(21.4 \%)$, and mixed lesions in $20(35.7 \%)$ patients. In group II, 8 patients $(66.6 \%)$ had severe mitral stenosis, one patient (8\%) had mitral regurgitation and 3 patients had mixed lesions (25\%). Tricuspid regurgitation (TR) was severe in $80.35 \%$ of patients in group I and in $100 \%$ of patients in group II $(p=0.19)$. The baseline characteristics of these patients are shown in Table 1.

The mitral valve was approached through the left 
Table 1. Comparison of baseline characteristics of the two groups.

\begin{tabular}{|c|c|c|c|c|}
\hline & & Group I $(\mathrm{n}=56)$ & Group II $(\mathrm{n}=12)$ & $\mathrm{p}$ value \\
\hline \multicolumn{2}{|l|}{ Mean age (years) (range) } & $30.80(14-46)$ & $33.58(26-46)$ & 0.207 \\
\hline \multicolumn{2}{|l|}{ Sex ratio (male:female) } & $1: 1.24(25: 31)$ & $1: 1.4(5: 7)$ & 0.85 \\
\hline \multirow{2}{*}{ NYHA class } & III & 32 & 4 & \multirow{2}{*}{0.134} \\
\hline & IV & 16 & 8 & \\
\hline \multirow{3}{*}{ Lesion in mitral valve } & Dominant stenosis & $24(42.8 \%)$ & $8(66.6 \%)$ & \multirow{3}{*}{0.29} \\
\hline & Dominant regurgitation & $12(21.4 \%)$ & $1(8 \%)$ & \\
\hline & Mixed lesion & $20(35.7 \%)$ & $3(25 \%)$ & \\
\hline \multicolumn{2}{|l|}{ Atrial fibrillation } & $36(64.28 \%)$ & $9(75 \%)$ & 0.738 \\
\hline \multirow{2}{*}{ Tricuspid regurgitation } & Moderate & $11(19.64 \%)$ & 0 & \multirow{2}{*}{0.19} \\
\hline & Severe & $45(80.35 \%)$ & $12(100 \%)$ & \\
\hline \multicolumn{2}{|c|}{ Mean duration of symptoms (Range) } & 2.3 years ( 5 months -5 years) & 3.2 years $(1$ year -12 years $)$ & 0.363 \\
\hline
\end{tabular}

NYHA: NEW YORK HEART ASSOCIATION.

atrium in $262(96.3 \%)$ patients and in the remaining 10 (3.67\%) patients, trans-septal approach was used. Complete or partial preservation of chordal apparatus was possible in majority of patients $(97.05 \%$ i.e. 264 out of 272 patients). De Vega tricuspid annuloplasty was performed in 8 patients in group I and in 4 patients in group II $(\mathrm{p}=0.203)$. The mean CPB time was $72 \pm 20$ minutes in group I and $102 \pm 25$ minutes in group II $(\mathrm{p}<0.001)$ and the aortic cross clamp time was $48 \pm 18$ minutes in group I and $55 \pm 28$ minutes in group II $(\mathrm{p}=0.078)$. These operative data are depicted in Table 2.

The preoperative and postoperative changes in hemodynamics of the two groups are presented in Table 3. Group II patients had a higher baseline mean PA pressure, systolic PA pressures, PCWP and PVR but lower cardiac index than group I patients $(\mathrm{p}<0.05)$. In group I, the mean PAP fell by $34.49 \%$ from a mean preoperative level of $58 \pm 8$ to $38 \pm 8 \mathrm{mmHg}$, 6 hours following MVR $(p<0.001)$ and it continued to decrease over the next 24 hours $(\mathrm{p}<0.001)$. Systolic PA pressures fell from 79 $\mathrm{mmHg}$ preoperatively to $46 \mathrm{mmHg}$ after 6 hours and to $39 \mathrm{mmHg} 24$ hours after the surgery $(\mathrm{p}<0.001)$. PCWP decreased by $60 \%$ from 35 to $14 \mathrm{mmHg}$ within 6 hours of surgery. Similarly, the pulmonary vascular resistance (PVR) decreased by $51 \%$ from a mean preoperative value of 518 to 254 dyne $\cdot \mathrm{s} \cdot \mathrm{cm}^{-5}$ six hours after MVR (p $<0.001$ ). Mean cardiac index increased from 1.98 to 2.86 $\mathrm{L} \cdot \min ^{-1} \cdot \mathrm{m}^{-2}(\mathrm{p}<0.001)$ in the same duration (Table 3, Figures 1 and 2 )

In group II, the mean PAP decreased by $24.27 \%$ from a mean preoperative level of $82 \pm 10$ to $60 \pm 8 \mathrm{~mm} \mathrm{Hg}$ within six hours following MVR $(\mathrm{p}<0.001)$; it decreased over the next 24 hours but this decrease was not statistically significant. Systolic PA pressures decreased by $33.01 \%$ from $103 \pm 17$ to $69 \pm 12 \mathrm{mmHg}$ in 6 hours after MVR but further decrease was only $3.89 \%$ in next 18 hours. PCWP decreased to a mean of 26 from $40 \pm 11$ $\mathrm{mmHg}$ in initial 6 hours of surgery and further decreased to $22 \mathrm{mmHg}$ at 24 hours postoperatively $(\mathrm{p}<0.05)$. The PVR decreased by $24 \%$ from a mean preoperative value of $778 \pm 124$ to $591 \pm 70$ dyne $\cdot \mathrm{s} \cdot \mathrm{cm}^{-5}$ six hours after MVR ( $p<0.001$ ). Pulmonary vascular resistance continued to decrease significantly even after that (Table 3, Figures 1 and 2). This group of patients showed persistent low cardiac output even after MVR. Mean cardiac index increased marginally from 1.3 to $1.58 \mathrm{~L} \cdot \mathrm{min}^{-1} \cdot \mathrm{m}^{-2}$. This increase was however statistically significant $(\mathrm{p}=0.001)$.

Patients in group II needed to be mechanically ventilated postoperatively for a longer duration $(32.2 \pm 21.4$ hours vs $21.5 \pm 11.7$ hours $)(p=0.04)$. Inotropic support in the form of epinephrine, dobutamine and vasodilators like nitroglycerine was also required for a longer duration in group II patients but it was not statistically significant. Post-operative Echo during the ICU stay revealed RVSP $\geq 50 \mathrm{mmHg}+$ RAP (severe PAH) in 35 $(62.5 \%)$ patients of group I and severe PAH in $7(58.3 \%)$ patients of group II. The duration of ICU stay was longer in group II compared to group I $(p=0.032)$, but the duration of hospital stay was comparable $(\mathrm{p}=0.078)$. Two patients from group I (3.5\%) and two patients from group II $(16.6 \%)$ died in the immediate post-operative period constituting an overall mortality rate of $5.8 \%$ (Table 2 ). Although this difference is large, it did not reach statistical significance because of small sample size of group II. Both deaths in group II were caused by persistent low cardiac output due to right ventricular dysfunction. The two patients in group I died because of low cardiac output syndrome and sepsis. 
Table 2. Comparison of operative data and post-operative course in the two groups.

\begin{tabular}{|c|c|c|c|c|}
\hline & & Group I $(\mathrm{n}=56)$ & Group II $(n=12)$ & $\mathrm{p}$ value \\
\hline \multicolumn{2}{|c|}{ Cardio pulmonary bypass time (min.) } & $72 \pm 20$ & $102 \pm 25$ & $<0.001$ \\
\hline \multicolumn{2}{|c|}{ Aortic cross clamp time (min.) } & $48 \pm 18$ & $55 \pm 28$ & 0.078 \\
\hline \multicolumn{2}{|c|}{ De vega's tricuspid annuloplasty } & 8 & 4 & 0.203 \\
\hline \multicolumn{2}{|c|}{ Elective ventilation time (hours) } & $21.5 \pm 11.7$ & $32.2 \pm 21.4$ & 0.04 \\
\hline \multirow{2}{*}{ Epinephrine } & Used (n, \%) & $50(89.28 \%)$ & $12(100 \%)$ & 0.58 \\
\hline & Duration (days) & $2.3 \pm 1.9$ & $3.4 \pm 2.5$ & 0.51 \\
\hline \multirow{2}{*}{ Nitroglycerine } & Used (n, \%) & $56(100 \%)$ & $12(100 \%)$ & - \\
\hline & Duration (days) & $2.5 \pm 1.8$ & $3.2 \pm 1.6$ & 0.71 \\
\hline \multirow{2}{*}{ Dopamine } & Used (n, \%) & $52(92.85 \%)$ & $10(83.33 \%)$ & 0.285 \\
\hline & Duration (days) & $3.1 \pm 1.2$ & $3.8 \pm 2$ & 0.72 \\
\hline \multirow{2}{*}{ Dobutamine } & Used (n, \%) & $32(57.14 \%)$ & $8(66.66 \%)$ & 0.78 \\
\hline & Duration (days) & $3.6 \pm 2.6$ & $5.1 \pm 2.2$ & 0.55 \\
\hline \multicolumn{2}{|c|}{ ICU stay (days) } & $2 \pm 1$ & $4 \pm 3$ & 0.032 \\
\hline \multicolumn{2}{|c|}{ Hospital stay (days) } & $8 \pm 4$ & $12 \pm 7$ & 0.078 \\
\hline \multicolumn{2}{|c|}{ Mortality } & $2(3.5 \%)$ & $2(16.6 \%)$ & 0.41 \\
\hline
\end{tabular}

ICU: Intensive care unit.

Table 3. Preoperative, intraoperative and postoperative hemodynamics of groupI patients and group II patients.

\begin{tabular}{cccccccccccc}
\hline & \multicolumn{2}{c}{ Base line } & \multicolumn{2}{c}{ Post intubation } & \multicolumn{2}{c}{$\begin{array}{c}\text { 6 hours } \\
\text { postoperatively }\end{array}$} & \multicolumn{2}{c}{$\begin{array}{c}\text { 24 hours } \\
\text { postoperatively }\end{array}$} & \multicolumn{2}{c}{$\begin{array}{c}48 \text { hours } \\
\text { postoperatively }\end{array}$} \\
\cline { 2 - 12 } & Group I & Group II & Group I & Group II & Group I & Group II & Group I & Group II & Group I & Group II \\
\hline MPAP (mmHg) & $58 \pm 8$ & $82 \pm 10^{*}$ & $48 \pm 8$ & $75 \pm 15$ & $38 \pm 6^{*}$ & $60 \pm 8^{*}$ & $30 \pm 4^{*}$ & $56 \pm 8$ & $24 \pm 6$ & $46 \pm 11$ \\
Systolic PAP (mmHg) & $79 \pm 14$ & $103 \pm 17^{*}$ & $68 \pm 10$ & $92 \pm 16$ & $46 \pm 8^{*}$ & $69 \pm 12^{*}$ & $39 \pm 7^{*}$ & $65 \pm 8$ & $32 \pm 10$ & $61 \pm 9$ \\
PCWP (mmHg) & $35 \pm 12$ & $40 \pm 11^{*}$ & $27 \pm 10$ & $34 \pm 8$ & $14 \pm 4^{*}$ & $26 \pm 5^{*}$ & $13 \pm 4$ & $22 \pm 5^{*}$ & $12 \pm 5$ & $20 \pm 6$ \\
CI (lt./min $\left./ \mathrm{m}^{2}\right)$ & $1.9 \pm 0.4$ & $1.3 \pm 0.2^{*}$ & $2.2 \pm 0.5^{*}$ & $1.38 \pm 0.3$ & $2.86 \pm 0.8^{*}$ & $1.5 \pm 0.4^{*}$ & $3.02 \pm 0.8^{*}$ & $1.70 \pm 0.3^{*}$ & $2.91 \pm 0.4$ & $1.86 \pm 0.8$ \\
PVR (dynes $\left.\cdot \mathrm{sec} \cdot \mathrm{cm}^{-5} / \mathrm{m}^{2}\right)$ & $518 \pm 184$ & $778 \pm 124^{*}$ & $502 \pm 168$ & $744 \pm 112$ & $254 \pm 120^{*}$ & $591 \pm 70^{*}$ & $231 \pm 104^{*}$ & $558 \pm 68^{*}$ & $192 \pm 86$ & $524 \pm 57$ \\
\hline
\end{tabular}

$\mathrm{PAP}=$ pulmonary arterial pressure, $\mathrm{PVR}=$ pulmonary vascular resistance, $\mathrm{PCWP}=$ pulmonary capillary wedge pressure, $\mathrm{CI}=$ cardiac index; ${ }^{*}$ Shows statistically significant change in hemodynamics $(\mathrm{p}<0.05)$.

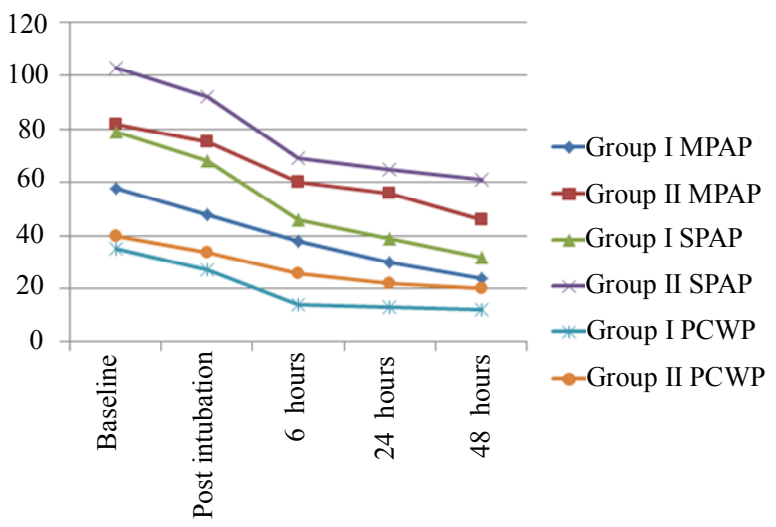

Figure 1. Changes in mean PAP, systolic PAP and PCWP in preoperative, intraoperative and postoperative periods in both groups.

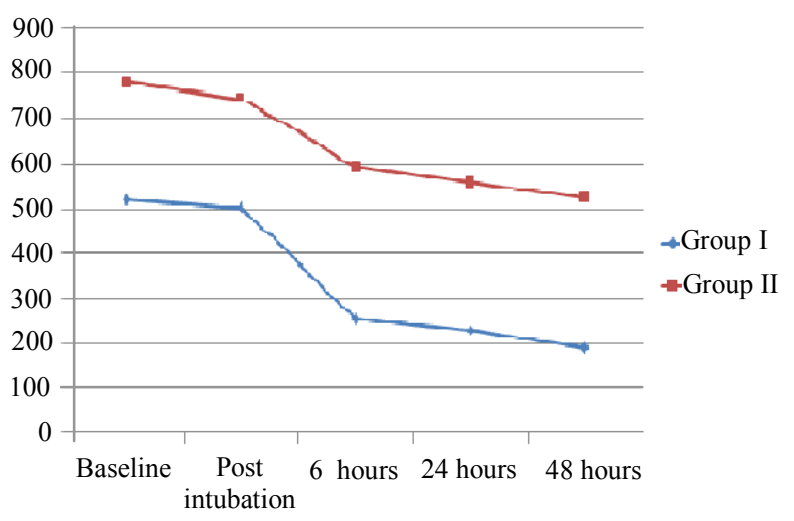

Figure 2. Changes in pulmonary vascular resistance (PVR) in preoperative, intraoperative and postoperative periods in both groups. 
There was no operative mortality for routine MVR without significant PAH $(\mathrm{n}=204)$ at our institute during this period.

Complications recorded in the surviving patients during hospital stay were bleeding leading to re-exploration in two patients, jaundice in one patient and renal dysfunction in three patients and at follow-up, thromboembolic episodes in two patients.

At follow-up, patients were assessed for symptomatic improvement and by echocardiography at 1 month and 12 months post-operatively. Follow up was $100 \%$ complete in the 64 surviving patients. At one month followup, 48 patients $(88.8 \%)$ were in NYHA class II in group I and $9(90 \%)$ patients of the survivors were in NYHA class II in group II which was also statistically not significant. Echocardiography showed severe PAH in 42 patients $(77.7 \%)$ in group I versus 10 patients of group II (100\%). At 12 months follow-up, among the 64 survivors, there were 3 deaths, two of which were in group I and the other in group II. Patients were assessed for severe PAH, by echocardiography, which was prevalent in 38 patients $(73.0 \%)$ in group I and in 9 patients $(100 \%)$ in group II.

\section{Limitations}

Our study has a few limitations which we could not address. The period of study from which patients have been selected is one year during which we could get only 68 patients who required isolated mitral valve replacement and had severe PAH. The number of patients in group II (patients with severe PAH and supra-systemic pressures) is quite small and hence conclusions are not significant. Another limitation is we have included patients with both mitral stenosis and mitral regurgitation who have different pathophysiologies and different post-operative behaviour. However due to small numbers, we included both the categories of patients for study. Lastly, inhalational nitric oxide could not be used due to its non-availability at our centre.

\section{Discussion}

The results of our study indicate that even though there is a significant improvement in hemodynamics of patients with severe PAH after MVR, this improvement is less spectacular in patients who have supra-systemic PA pressures (Group II in our study). The mortality rate of MVR is also significantly higher in this subgroup of patients. In these patients the decrease in mean PA pressures, systolic PA pressures, PCWP and PVR is less significant compared to those patients who have severe $\mathrm{PAH}$, but in whom the PA pressures are at or below systemic levels. Pulmonary artery hypertension commonly complicates mitral valve disease. This is more frequently seen in the Indian population where unlike the western population the etiology is commonly rheumatic and presented at a younger age [1]. Thus, by the time these patients present, they often have advanced disease and severe PAH. The pathophysiology of severe PAH is related to increased pressure overload in mitral stenosis and volume overload in mitral regurgitation. With progression of disease, PVR also increases due to reactive pulmonary vasoconstriction and organic changes in the pulmonary microvasculature. The presence of severe PAH not only has an influence on the prognosis of mitral valve disease, it also affects the postoperative outcome as borne by several studies [4-19]. Some authors have shown that severe PAH regresses after MVR/mitral valve repair [4-15]. However, others have shown that severe PAH is associated with higher postoperative mortality especially in patients with supra-systemic PA pressures [15-25]. This has also been our experience. The higher mortality seen in group II could be attributed to a more severe form of the illness due to earlier onset and more longstanding disease. This has been believed to lead to refractory right ventricular failure in the post-operative period $[14,16]$. Even optimal anaesthesia, agents like midazolam and fentanyl and post-operative management in the form of use of vasodilators, high $\mathrm{FiO}_{2}$ and elective post-operative ventilation fail to reduce the high post-operative mortality in supra-systemic PAH to acceptable levels.

One drawback with our study was our inability to use nitric oxide (NO) due to its non-availability. This could well be a factor for the higher post-operative mortality in our series [26]. However other reports from developing countries have documented good results even without $\mathrm{NO}$ and NO is not widely available in most Indian hospitals [29]. Therefore blanket recommendations for the use of NO in all these patients cannot be made, primarily for logistical reasons. Other studies have reported similar results in patients with severe $\mathrm{PAH}$ and mild $\mathrm{PAH}$ and return of PA pressures and PVR to near normal values in both groups [27]. However, they have not electively studied patients with suprasystemic PA pressures, as we have done in our study. In patients with less severe elevation in PA pressures the significant decrease in PA pressures and PVR can be attributed to correction of valvular pathology, thus relieving the passively elevated PA pressures as well as the reactive vasoconstriction, which happens well in the post-operative period. Sudden reduction in PA pressures and PVR may occur due to acute reduction in LA pressures and reversal of pulmonary vasoconstriction. The increase in cardiac index is attributed to the improvement in right ventricular function. The residual elevated PVR in group II is probably caused by ireversible changes in pulmonary microvasculature [28,29]. The mortality rate of $3.5 \%$ and $16.5 \%$ in our study compare well with those in the literature, where mortality has been reported to the $15 \%-31 \%[1,2,29]$. Najafi et al. 
found that degree of PAH correlated strongly with mortality, being $16 \%$ in patients with mild PAH and $61 \%$ in patients where PAP was systemic [30]. Barclay et al. even consider a systolic PA pressure $\geq 110 \mathrm{mmHg}$ to be an absolute contraindication for surgery [18]. In recent reports the mortality has improved in patients with severe PAH to $2.3 \%-10 \%$ [31-34]. This is also borne out of our study, where we have a mortality of $3.5 \%$. This has been attributed to better prosthesis for valve replacement and better post-operative care. Complete or partial preservation of subvalvular apparatus has also contributed to improved post-operative results. We could preserve the subvalvular apparatus (partial posterior chordal preservation) in $97 \%$ of our patients.

To conclude, PAP returns to near normal values in the majority of patients with severe PAH after MVR. However, the decrease is less significant in patients with very severe PAH/supra-systemic PA pressures. This subgroup of patients carries a higher mortality.

\section{Acknowledgements}

The author would like to wishfully thank the work done by Dr. P. Jagadesan, Dr. K. Vikram \& Mr. Manoharan, New Delhi, for the help provided in analysing the data and presenting it in tables $\&$ figures.

\section{REFERENCES}

[1] S. Padmavati, "Present Status of Rheumatic Fever and Rheumatic Heart Disease in India," Indian Heart Journal, Vol.47, 1995, pp. 395-398.

[2] J. S. Chaffin and W. M. Daggett, "Mitral Valve Replacement: A Nineyear Follow-Up Ofrisks and Survivals," The Annals of Thoracic Surgery, Vol. 27, No. 4, 1979, pp. 312-319. doi:10.1016/S0003-4975(10)63305-X

[3] C. Ward and B. W. Hancock, "Extreme Pulmonary Hypertension Caused by Mitral Valvedisease. Natural History and Results of Surgery," British Heart Journal, Vol. 37, No. 1, 1975, pp. 74-78. doi:10.1136/hrt.37.1.74

[4] J. C. Zener, E. W. Hancock, N. E. Shumway, et al., "Regression of Extreme Pulmonary Hypertension after Mitral Valve Surgery," American Journal of Cardiology, Vol. 30, No. 8, 1972, pp. 820-826. doi:10.1016/0002-9149(72)90005-7

[5] A. G. Morrow, H. N. Oldham, R. S. Elkins, et al., "Prosthetic Replacement of Mitralvalve. Preoperative and Postoperative Clinical and Hemodynamic Assessments in 100 Patients," Circulation, Vol. 35, 1967, pp. 962-979. doi:10.1161/01.CIR.35.5.962

[6] T. K. Kaul, W. H. Bain, J. V. Jones, et al., "Mitral Valve Replacement in the Presence of Severe Pulmonary Hypertension," Thorax, Vol. 31, No. 3, 1976, pp. 332-336. doi:10.1136/thx.31.3.332

[7] J. B. McIlduff, W. M. Daggett, M. J. Buckley, et al., "Systemic and Pulmonary Hemodynamic Changes Immediately Following Mitral Valve Replacement in Man,"
The Journal of Cardiovascular Surgery, Vol. 21, 1980, pp. 261-266.

[8] J. Hamer, T. Boulton, J. Fleming, et al., "Mitral Valve Replacement: Long-Term Results, with Particular Reference to Changes in Pulmonary Vascular Resistance," Thorax, Vol. 23, 1968, pp. 1-10. doi:10.1136/thx.23.1.1

[9] K. Hollinrake, M. Baidya and M. H. Yacoub, "Haemodynamic Changes in Patientswith high Pulmonary Vascular Resistance after Mitral Valve Replacement. Comparative Study between Use of Unstented Aortic Homograft Valves and Starr-Edwards Prostheses," British Heart Journal, Vol. 35, No. 7, 1973, pp. 1047-1054. doi:10.1136/hrt.35.10.1047

[10] B. D. Foltz, E. A. Hessel and T. D. Ivey, "The Early Course of Pulmonary Artery Hypertension in Patients Undergoing Mitral Valve Replacement with Cardioplegic Arrest," The Journal of Thoracic and Cardiovascular Surgery, Vol. 88, No. 2, 1984, pp. 238-247.

[11] M. L. Camara, A. Aris, J. M. Padro, et al., "Long-Term Results of Mitral Valve Surgeryin Patients with Severe Pulmonary Hypertension," The Annals of Thoracic Surgery, Vol. 45, 1988, pp.133-136. doi:10.1016/S0003-4975(10)62423-X

[12] J. E. Dalen, J. M. Matloff, G. L. Evans, et al., "Early Reduction of Pulmonary Vascular Resistance after Mitral Valve Replacement," The New England Journal of Medicine, Vol. 277, No. 8, 1967, pp. 387-394. doi:10.1056/NEJM196708242770801

[13] J. M. Manners, J. L. Monro and J. K. Ross, "Pulmonary Hypertension in Mitral Valve Disease: 56 Surgical Patients Reviewed," Thorax, Vol. 32, No. 6, 1977, pp. 691696. doi:10.1136/thx.32.6.691

[14] M. N. D’Ambra, P. J. LaRaia, D. M. Philbin, et al., "Prostaglandin E1: A New Therapy for Refractory Right Heart Failure and Pulmonary Hypertension after Mitral Valve Replacement," The Journal of Thoracic and Cardiovascular Surgery, Vol. 89, 1985, pp. 567-572.

[15] A. Walston, R. H. Peter, J. J. Morris, et al., "Clinical Implications of Pulmonary Hypertension in Mitral Stenosis," American Journal of Cardiology, Vol. 32, No. 5, 1973, pp. 650-655. doi:10.1016/S0002-9149(73)80058-X

[16] V. Datt, D. K. Tempe, M. A. Geelani, et al., “Atrial Septostomy for Acute Right Ventricular Failure Following Mitral Valve Replacement-A Case Report," Annals of Cardiac Anaesthesia, Vol. 7, 2004, pp. 62-66.

[17] P. G. Cevese, V. Gallucci, C. Valfre, et al., "Pulmonary Hypertension in Mitral Valvesurgery," Journal of Cardiovascular Surgery, Vol. 21, 1980, pp. 7-10.

[18] R. S. Barclay, J. M. Reid, J. G. Stevenson, et al., "LongTerm Follow-Up of Mitral Valve Replacement with StarrEdwards Prosthesis," British Heart Journal, Vol. 34, No. 2, 1972, pp. 129-133. doi:10.1136/hrt.34.2.129

[19] S. Simonsen, K. Forfang, A. Andersen, et al., "Hospital Mortality after Mitral Valve Replacement. Prognostic Significance of Preoperative Clinical and Hemodynamic Factors," Acta Medica Scandinavica, Vol. 195, No. 1-6, 1974, pp. 243-246.

doi:10.1111/j.0954-6820.1974.tb08132.x 
[20] T. Zielinski, H. Pogorzelska, A. Rajecka, et al., "Pulmonary Hemodynamics at Restand Effort, 6 and 12 Months after Mitral Valve Replacement: A Slow Regression of Effort Pulmonary Hypertension," International Journal of Cardiology, Vol. 42, 1993, pp. 57-62. doi:10.1016/0167-5273(93)90102-M

[21] W. G. Austen, H. B. Corning, J. M. Moran, et al., "Cardiac Hemodynamics Immediately Following Mitral Valve Surgery," The Journal of Thoracic and Cardiovascular Surgery, Vol. 51, 1966, pp. 468-473.

[22] S. J. Lee, A. J. Zaragoza, J. C. Callaghan, et al., "Hemodynamic Changes Following Mitral Valve Replacement with the Starr-Edwards and Cutter-Smeloff Prostheses," The Journal of Thoracic and Cardiovascular Surgery, Vol. 61, 1971, pp. 688-698. doi:10.1016/0002-8703(68)90086-0

[23] H. Hultgren, H. Hubis and N. Shumway, "Cardiac Function Following Mitral Valve Replacement," American Heart Journal, Vol. 75, No. 3, 1968, pp. 302-312.

[24] M. S. Hochberg, W. M. Derkac, D. M. Conkle, et al., "Mitral Valve Replacement in Elderly Patients: Encouraging Postoperative Clinical and Hemodynamic Results," The Journal of Thoracic and Cardiovascular Surgery, Vol. 77, 1979, pp. 422-426.

[25] S. Nitter-Hauge, T. Froysaker and K. V. Hall, "Clinical and Hemodynamic Findings Following Prosthetic Valve Replacement for Mitral Valve Disease. A Study of Patients with the New Björk-Shiley Tilting Disc Valve," Acta Medica Scandinavica, Vol. 200, No. 1-6, 1976, pp. 215-221. doi:10.1111/j.0954-6820.1976.tb08222.x

[26] R. H. Clark, T. J. Kueser and M. W. Walner, "Low-Dose Nitric Oxide Therapy for Persistent Pulmonary Hypertension of the Newborn. Clinical Inhaled Nitric Oxide Research Group," The New England Journal of Medicine, Vol. 342, 2000, pp. 469-474. doi:10.1056/NEJM200002173420704

[27] Tempe, Hasija, Datt, Tomar, Virmani and Banerjee, "Evaluation and Comparison of Early Hemodynamic Changes after Elective Mitral Valve Replacement in Patients with Severe and Mild Pulmonary Arterial Hypertension," The Journal of Thoracic and Cardiovascular Surgery, Vol. 23, 2009, pp. 298-305.

[28] E. Braunwald, "Valvular Heart Disease," In: E. Braunwald, Heart Disease, 7th Edition, Saunders, Philadelphia, 2005.

[29] Mubeen, A. K. Singh, S. K. Agarwal, J. Pillai, S. Kapoor and A. K. Srivastava, "Mitral Valve Replacement in Severe Pulmonary Arterial Hypertension," Asian Cardiovascular and Thoracic Annals, Vol. 16, No. 1, 2008, pp. 37-42. doi:10.1177/021849230801600110

[30] H. Najafi, W. Dye, H. Javid, J. A. Hunter, W. E. Ostermiller and O. C. Julian, "Mitral Valve Replacement: Review of Seven Years' Experience," American Journal of Cardiology, Vol. 24, 1969, pp. 386-392. doi:10.1016/0002-9149(69)90433-0

[31] O. Jegaden, R. Rossi, F. Delahaye, P. Montagna, J. Delaye, J. P. Delahaye, et al., "Mitral Valve Replacement in Severe Pulmonary Hypertension. Long-Term Results [Review]," Archives des Maladies du Coeur et des Vaisseaux, Vol. 84, 1991, pp. 1297-1301.

[32] M. L. Camara, A. Aris, J. Padro and J. M. Caralps, "Long-Term Results of Mitral Valve Surgery in Patients with Severe Pulmonary Hypertension," The Annals of Thoracic Surgery, Vol. 45, No. 2, 1988, pp. 133-136. doi:10.1016/S0003-4975(10)62423-X

[33] R. A. Cesnjevar, R. Feyrer, F. Walther, F. O. Mahmoud, Y. Lindemann and J. von derEmde, "High-Risk Mitral Valve Replacement in Severe Pulmonary Hypertension30 Years' Experience," European Journal Cardio-Thoracic Surgery, Vol. 13, 1998, pp. 344-352. doi:10.1016/S1010-7940(98)00042-6

[34] J. J. Vincens, D. Temizer, J. R. Post, L. H. Edmunds Jr. and H. C. Herrmann, "Long-Term Outcome of Cardiac Surgery in Patients with Mitral Stenosis and Severe Pulmonary Hypertension," Circulation, Vol. 92, No. S2, 1995, pp. 137-1342. doi:10.1161/01.CIR.92.9.137 